\title{
A Benchmarking Analysis of Digital Divide among Citizens: The Italian Evidence
}

\author{
Elisa Pautasso, Enrico Ferro \\ Istituto Superiore Mario Boella \\ Torino, Italy
}

\author{
Elisabetta Raguseo \\ Politecnico di Torino \\ Torino, Italy
}

\begin{abstract}
This paper analyses the digital divide among citizens, considered as differences between Internet users and non-users. To this aim data collected by the Piedmont ICT Observatory through a survey on a sample of 2,000 citizens since 2005 are studied through descriptive and multivariate analysis and then compared with Eurostat data. Specifically, the research shows that between 2005 and 2009 in Piedmont the number of Internet users has not noticeably grew up, while in the following two years the trend has changed and digital divide seems to have reduced. Which are the causes for this situation? As results, we have found out firstly the factors that determine Internet usage by individuals and then analysed possible policy solutions. Both the analysis of Piedmont data and the comparison with European countries showed that age and education are two main variables that impact on the usage of the Internet. Moreover the study reveals the presence of a gap in ICT diffusion between Piedmont and European regions in terms of policy implementation. Finally, the analysis of European e-inclusion policies provides some suggestions for the definition of future regional initiatives aimed to further strengthen the Information Society .
\end{abstract}

\section{Introduction}

Nowadays Information and Communication Technologies (ICT) play a key role in the development of the society. Especially in last decades, citizens, enterprises and governments have obtained benefits by using the Internet and the technologies, such as time reduction, cost savings and improvements of the communication patterns [1]. In spite of these evident advantages, in almost all European regions a variable percentage of the population is still excluded from the usage of all information technologies. Furthermore, Eurostat data show different ICT usage rates between European regions. By considering all these aspects, the aim of this paper is to discuss the digital divide in the European context, defined by OECD as 'differences between individuals, households, companies, or regions related to the access and usage of ICT'[2].
In such a context, Van Dijk [3] identifies 4 types of digital divide:

1. Material access (have / have not): it considers problems related to physical access to technologies;

2. Motivational access (want / want not): Prior to physical access comes the wish to have a computer and to be connected to the Internet. Many of those who remain on the "wrong" side of the digital divide have motivational problems.

3. Skills access (are able / are not able): This kind of digital divide is related to differences in ICT skills. After having acquired the motivation to use computers and some kind of physical access to them, individuals have to learn to manage the technologies.

4. Usage access (use enough / not use enough): this kind of digital divide is linked with the differences in the quality of ICT usage and can be observed when the previous types of digital divide (access, motivational and skills) are overcome.

Referring to the previous definition and analysing data collected in Piedmont, a region in the North-West of Italy, our work will focus on barriers for not using the Internet, considering digital divide in terms of "motivational access". Data collected from 2005 to 2009 by Piedmont ICT Observatory (PICTO) show that in Piedmont the Internet diffusion process seemed to have reached a plateau leaving about $50 \%$ of the population excluded. This is the starting point that led us to identify factors that determine Internet usage by citizens firstly in order to understand how to overcome the problem and then to identify possible policy implications. The research questions that the article aims to answer are the following:

- Which variables determine Internet usage by citizens?;

- Is it possible to increase the number of Internet users in European regions?;

- Which and how e-inclusion policies could be implemented? 
The main goal of this paper is thereby to define effective e-inclusion policies that could be useful in a European region in which the actual Internet usage rate is still low. This objective will be obtained through three steps:

- Analysis of the features of citizens that are still excluded from the Information Society;

- Identification of the reasons for which citizens do not use the Internet;

- Enumeration of the e-inclusion policies adopted in some European countries where the percentage of Internet users is higher and evaluation of whether and how they could be replicated in the regional context that has been considered.

Therefore, analysing data collected between 2005 and 2009 we will be able to identify factors that determine Internet usage by citizens. In order to complete the description the final part of the study provides some insights about the Internet diffusion among citizens in Piedmont in 2011 underling that the percentage of Internet users at last has grew up, identifying which new groups of the population have been involved in the Information Society, which actions have been carried out in order to obtain such an increase and, finally, guessing which new directions future e-inclusion policies should follow.

The paper is structured as follows: Section 2 provides a literature review on the digital divide conceptual construct; Section 3 presents the methodology followed; Section 4 contains main results of PICTO and Eurostat data analysis, while in Section 5 a policy analysis is presented. Finally, Section 6 shows concluding remarks and possible future research directions.

\section{Literature review}

In 2001 OECD defined digital divide as 'differences between individuals, households, companies, or regions related to the access and usage of ICT'. This concept has changed and developed over years and many researchers have studied this phenomenon.

As it has been said before, Van Dijk [3] identifies 4 types of digital divide: material access, motivational access, skills access and usage access. This paper is focused on the divide due to the differences between people using and not using the Internet (material access). This kind of digital divide has been already studied by many authors in the past years: in 2003 Rice \& Katz [4] indicated the differences between Internet and mobile usage by citizens by using regression models with some demographic indicators as independent variables (income, race, gender, work status, marital status, education). They found out that the gap between Internet users and non-users could be associated to their income and age, but no longer with gender and race. Furthermore, similar relationships were identified considering mobile usage and the quality and frequency of Internet use. Also Selwyn [5] studied digital divide as differences between Internet users and non-Internet users by using logistic regression models and demonstrating that Internet usage depends on the adoption of other technologies, gender, age, education attainments and occupation. These dependencies were discovered also by $\mathrm{Di}$ Maggio [6] that, using descriptive data analysis, argued that Internet usage is linked to the place of residence, employment status, income, education attainments, race - ethnicity, age, gender and family structure. In particular he provided evidence that the study of the differences between groups of people with similar characteristics helps to better understand which services can be offered. Another interesting study was the one conducted by Roe [7] who used regression models to indicate that level of education is the strongest predictor variable of computer disquietude, followed by age and then gender. Finally, Kovacic [8] by using loglinear regression combined with classification trees has identified variables that cause Internet usage in order to provide policy implications.

Considering pros and cons of each of those methods, in this paper, regression and classification techniques are considered as the most suitable in order to:

- identify the relationship between Internet usage and a set of socio-demographic variables,

- understand which variables are the most important in this relationship,

- and, above all, classify the population in groups characterized by similar features.

The identification of the factors that lead to the exclusion from the Information Society could be helpful for policy makers who want to guarantee a better inclusion of all individuals in the Society.

Moreover many authors have sought why similar regions have reached different Internet usage rates. For example Vincente [9] makes a comparison between European regions finding which socio-economic indicators determine such differences. Similar analysis are given also by [10], [11], [12], [13], [14].

The analysis of the differences between regions is also useful to set out which policies could be adopted in each region. Many scholars have studied digital divide focusing on the definition of e-inclusion policies through the investigation of the needs of nonInternet users and the barriers in adopting the new technologies [15] and [16] or evaluating the implementation of policies in different countries [17].

In this paper, as shown in Figure 1, we integrate some of the methodologies presented above in order to present a complete analysis of the digital divide for the regional context considered: using different data sources we will show similar outputs that could be taken into account for the definition of adequate einclusion policies. 


\section{Methodology}

The figure below illustrates the methodology used for this research study. Data collected by Piedmont ICT Observatory (PICTO) are used to identify which variables determine Internet usage and the motivations for not using the Internet. Such data have been collected through CATI interviews on a sample of 2,000 citizens each year. The sample has been created considering 3 stratification variables: gender, age and place of residence. After the collection of the data, cases have been weighted to obtain a sample representative of the total population. In addition, Piedmont has been compared with other European regions so as to discover the presence of structural factors in the population that justify, in part, the Internet usage rate reached. Moreover, some einclusion policies implemented in other European regions have been evaluated (in terms of quality and time). Such initiatives could be considered as examples for policy makers that want to increase the percentage of Internet users in their regions.

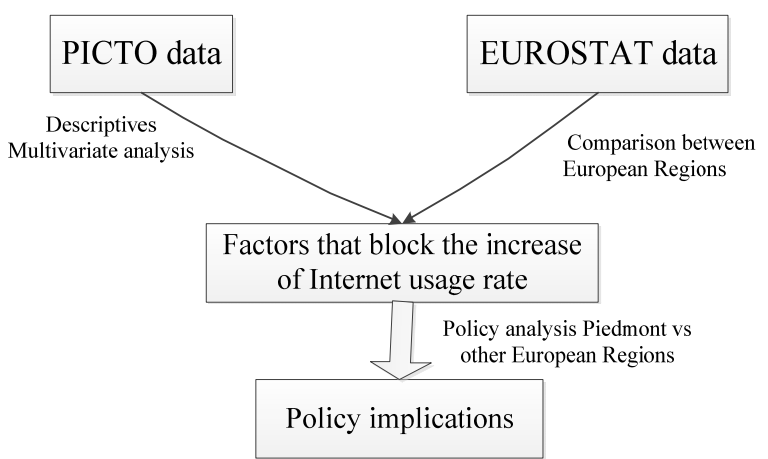

Figure 1. Research methodology scheme

\section{Results}

\subsection{Internet usage among citizens in Piedmont between 2005 and 2009}

The first part of this paper is aimed to discover which factors determine Internet usage by citizens: the case of the Piedmont region between 2005 and 2009 is used as an example useful to point out some of those barriers.

Data collected by PICTO indicates a little increase in the percentage of Internet users since 2005, reaching the value of $51 \%$ in 2009 . It means that almost half of Piedmont citizens in 2009 were still excluded from the Information Society.

Which are the causes that determined this situation? In order answer to this question the analysis at first focuses on variables that influence Internet usage and then considers motivations for not using the Internet.
Which variables influence Internet usage? Through multivariate analysis on data collected in 2009, the socio - demographic variables that influence Internet usage by citizens have been discovered.

The following variables have been considered:

1) Gender: male or female

2) Family size: 1, 2, 3, 4, 5 or more members

3) Occupation: employed, unemployed, student, retired, housewife

4) Education: low $=$ primary school degree, medium $=$ secondary school degree, high $=$ university or master

5) Family income (each month): $<1,000 € ; 1.000$ $2.000 € ; 2.000-2.500 € ; 2.500-4.500 €$; over $4.500 €$

6) Age: $16-24 ; 25-34 ; 35-44 ; 45-54 ; 55-64 ; 65-74$; over 75

7) Municipality size: $<10.000$ inhabitants; $10.000-$ 500.000 inhabitants; $>500.000$ inhabitants

8) Place of residence: $1=$ citizens that live in Turin province; $0=$ citizens that do not live in Turin province

A logistic regression model has been executed for identifying the relationship between Internet usage and the variables listed above. Even if correlation relationship between some of the independent variables considered subsists, the regression model is valid. The variance inflation factor (VIF) has been calculated [18] and we have found that multicollinearity does not invalidate the model. Specifically, the regression model shows that Internet usage depends on family size, age, education, family income and gender (Table 1).

Table 1. Results of the regression model on PICTO data (Internet usage in Piedmont), 2009

\begin{tabular}{|l|c|c|c|c|c|}
\hline $\begin{array}{l}\text { Independent } \\
\text { variables }\end{array}$ & $\boldsymbol{B}$ & S.E & Wald & Sig. & Exp (B) \\
\hline Gender & -0.483 & 0.121 & 15.913 & 0 & 0.617 \\
\hline Family size & 0.203 & 0.055 & 13.847 & 0 & 1.225 \\
\hline Employed & 0.471 & 0.514 & 0.839 & 0.36 & 1.601 \\
\hline Unemployed & -0.261 & 0.546 & 0.229 & 0.632 & 0.77 \\
\hline Student & 1.676 & 0.608 & 7.596 & 0.006 & 5.343 \\
\hline Retired & -0.104 & 0.53 & 0.038 & 0.845 & 0.902 \\
\hline Housewife & -0.527 & 0.541 & 0.95 & 0.33 & 0.59 \\
\hline Education & 1.094 & 0.084 & 168.442 & 0 & 2.985 \\
\hline $\begin{array}{l}\text { Family } \\
\text { income }\end{array}$ & 0.093 & 0.021 & 19.632 & 0 & 1.098 \\
\hline Age & -0.576 & 0.056 & 105.677 & 0 & 0.562 \\
\hline $\begin{array}{l}\text { Municipality } \\
\text { size }\end{array}$ & 0.019 & 0.103 & 0.034 & 0.854 & 1.019 \\
\hline $\begin{array}{l}\text { Place } \\
\text { residence }\end{array}$ & -0.117 & 0.16 & 0.535 & 0.464 & 0.89 \\
\hline
\end{tabular}

Cox \& Snell $\mathrm{R}^{2}$

0.413 


Nagelkerke R2
Overall \% of correct classification
$81 \%$

SOURCE: PICTO

Furthermore, using classification trees (Exhaustive CHAID Algorithm), the main variables that determine Internet usage have been picked out. The classification tree obtained from the analysis of data collected in 2009 points out that age and education attainments are the most important variables that influence Internet usage (Figure 2). In particular people younger than 44 can be classified in the majority of cases as Internet users, whereas, people older than 65 are mostly non Internet users. Finally, people between 45 and 65 years old can be defined as Internet users only if they have at least a degree.

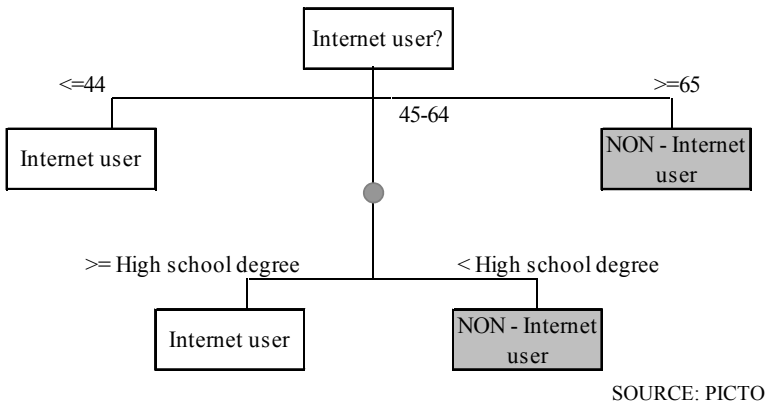

Figure 2. Classification tree on PICTO data (Internet usage in Piedmont), 2009

Motivations for not using the Internet. The research has then focused on non-Internet users. First of all, an analysis on the motivations for not using the Internet has been conducted. $65 \%$ of non-Internet users said that they were not interested in ICT, 19.6\% argued that they have no time enough and $14 \%$ have never tried, at least only $6 \%$ did not use Internet for access problems. Looking at each age group (Figure 3) the outcomes are different: in particular for increasing ages, the percentage of "not interested" in technologies grows up and for non-Internet users younger than 34 years old problems linked with time or access are more relevant than "not interest". Furthermore not having enough time is a relevant problem for people until 54 years old.

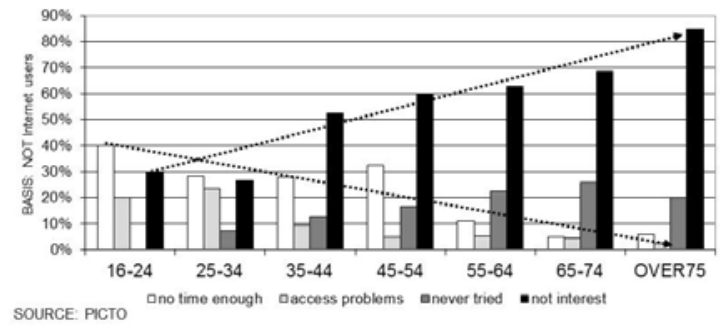

Figure 3. Motivation for not using Internet, by age groups, Piedmont, 2009
These outcomes indicate that non Internet users younger than 55 years (that revealed more tangible problems and represents $1 / 3$ of non-Internet users) could be more easily included in the Information Society through adequate policies than older people.

Moreover, comparing Internet and non-Internet users younger than 55 years old, education differences emerge. For non-Internet users compulsory school degree prevails, instead for Internet users high school degree overbear. Therefore also the lower education attainments of younger non-Internet users has to be considered when designing e-inclusion policies.

These findings are coherent with European Commission researches conducted on all European countries [19] and with other studies on the barriers for not using the Internet [15], [16].

\subsection{Comparison between Piedmont and similar European regions in 2009}

The next step of the analysis was aimed to collocate Piedmont in the European context and to understand if the Internet usage rate reached is coherent with other similar regions. To this purpose, based on the dimension of the countries in terms of number of inhabitants, we have decided to compare Piedmont with: 1) regions, in the case of the biggest countries ${ }^{1}$, 2) the whole country, in the case of the smallest states $^{2}$, where the number of inhabitants for each region was too small if compared with Piedmont population.

Looking at data about Internet usage by European citizens (source: Eurostat, 2009), 4 levels can be defined as follows:

- Low, for regions in which less than $40 \%$ of citizens use the Internet (South Italy, Greece, South-East Europe).

- Medium, for regions in which $40 \%-60 \%$ of citizens use the Internet (Spain, West France, Centre-North Italy, East Europe).

- Good: for regions in which $60 \%-75 \%$ of citizens use the Internet (Centre Europe).

- Optimum: for regions in which more than $75 \%$ of citizen use the Internet (North Europe).

According to this definition the value reached by Piedmont is "medium" but data confirm that the threshold of $50 \%$ can be overcome.

The analysis of the differences between Piedmont and countries with at least more than $60 \%$ of Internet users is useful to identify the reasons for Piedmont lateness. Looking at some economic indicators (income and GDP), Piedmont seemed to be similar to such regions (Table 2).

\footnotetext{
${ }^{1}$ Germany, France, Great Britain, Italy, Poland, Romany, Spain ${ }^{2}$ Belgium; Bulgaria; Czech Republic; Denmark; Estonia; Ireland; Greece; Latvia; Lithuania; Hungary; Netherlands; Austria; Portugal; Slovenia; Slovakia; Finland; Sweden; Croatia; Norway
} 
Table 2. Comparison between Piedmont and other European regions (economic indicators), 2007

\begin{tabular}{|c|c|c|}
\hline & $\begin{array}{c}\text { Income } \\
(€ / \text { inhabitants) } *\end{array}$ & $\begin{array}{c}\text { GDP } \\
(€ / \text { inhabitants }) *\end{array}$ \\
\hline $\begin{array}{l}\text { Regions with } 60 \%- \\
75 \% \text { Internet users } \\
\end{array}$ & 17,910 & 27,023 \\
\hline $\begin{array}{l}\text { Regions with more } \\
\text { than } 75 \% \text { Internet } \\
\text { users }\end{array}$ & 22,369 & 36,506 \\
\hline Piedmont & 21,202 & 28,600 \\
\hline
\end{tabular}

Despite, focusing on the structure of the population, some differences are clearly visible (Table 3 ). In particular, they regard: 1) education attainments: in Piedmont the percentage of graduated workers is lower than in the other regions of the comparison; 2) industrial structure: in Piedmont the number of citizens working in the manufacturing sector is bigger than in the other regions; 3) ageing of the population: in Piedmont there are less young people and more elderly citizens than in other countries.

Table 3. Differences in the population (Piedmont vs regions with more than $60 \%$ Internet users), 2009

\begin{tabular}{|l|c|c|c|}
\hline & $\begin{array}{l}\text { Regions with } \\
60 \%-75 \% \\
\text { Internet users }\end{array}$ & $\begin{array}{l}\text { Regions with } \\
\text { users } \\
\text { use Internet }\end{array}$ & Piedmont \\
\hline $\begin{array}{l}\text { unemployment } \\
\text { rate }\end{array}$ & $7,7 \%$ & $5,7 \%$ & $4,2 \%$ \\
\hline $\begin{array}{l}\text { \% graduated } \\
\text { workers }\end{array}$ & $29,8 \%$ & $30,8 \%$ & $16,1 \%$ \\
\hline $\begin{array}{l}\text { \% workers } \\
\text { (manufacturing } \\
\text { sector) }\end{array}$ & $13,1 \%$ & $11,9 \%$ & $24,4 \%$ \\
\hline $\begin{array}{l}\text { \% workers (ICT } \\
\text { services sector) }\end{array}$ & $13,5 \%$ & $15,8 \%$ & $11,2 \%$ \\
\hline $\begin{array}{l}\% \text { citizens under } \\
30 \text { years }\end{array}$ & $19,2 \%$ & $18,0 \%$ & $13,0 \%$ \\
\hline $\begin{array}{l}\text { \% citizens over } \\
60 \text { years }\end{array}$ & $22,6 \%$ & $23,4 \%$ & $28,9 \%$ \\
\hline
\end{tabular}

SOURCE: PICTO, EUROSTAT

Furthermore looking at each age group and at each part of the population with the same education level, we have been able to better understand differences between Piedmont and some regions with more than $60 \%$ of Internet users. Figure 4 represents the percentage variation between the number of Internet users in Piedmont and in some countries with more than $60 \%$ of Internet users by age and education: the biggest differences in the number of Internet users are visible for people with more than 45 years and a lower education level.

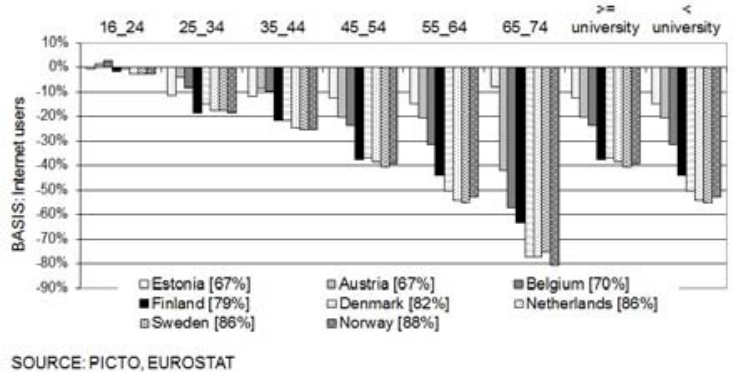

Figure 4. Differences in the \% of Internet users by age and education level between Piedmont and countries with more than $65 \%$ of Internet users, 2009

Results obtained splitting the population by age and education reveal that differences in the number of Internet users between Piedmont and the other European regions are evident for elder and less wellschooled people, instead, for example, the part of young (16-24 years old) citizens that use Internet is the same in Piedmont and in the other countries considered. Hence it would be useful to understand how European regions considered have been able to promote Internet usage between that part of the population that now has reached values considerably higher than Piedmont. In particular we are interested not only to analyse policies aimed at promoting Internet usage among elderly people (that as shown in Figure 3 are simply "not interested") but above all individualize actions addressed to adults non Internet users (e.g. citizens younger 55 with a low education level) that represent a significant quote of non-Internet users and seem to be more interested in technologies if they discover their utility and benefits .

Finally the lag between Piedmont and the regions / countries that have more than $60 \%$ of Internet users has been calculated as follows:

Table 4. Piedmont Lag

\begin{tabular}{|c|c|c|}
\hline & Country & $51 \%$ Internet users (year) \\
\hline & Piedmont & 2009 \\
\hline \multirow{6}{*}{ 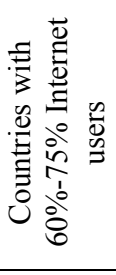 } & Ireland & 2007 \\
\hline & Latvia & 2007 \\
\hline & Slovakia & 2007 \\
\hline & Estonia & 2005 \\
\hline & Austria & 2006 \\
\hline & Belgium & 2005 \\
\hline \multirow{5}{*}{ 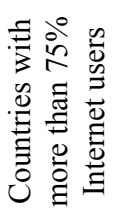 } & Finland & $2003(58 \%)$ \\
\hline & Denmark & $2003(64 \%)$ \\
\hline & Netherlands & $2005(74 \%)$ \\
\hline & Sweden & $2003(69 \%)$ \\
\hline & Norway & $2003(66 \%)$ \\
\hline
\end{tabular}


For each country Table 4 indicates the year in which the percentage of Internet users was 51\% (value for Piedmont region in 2009) ${ }^{3}$. Piedmont delay is equal to 3-5 year if compared with regions in which Internet usage rate is defined as "good", while it is about 10 year for the countries in which the rate is "optimum".

\subsection{Piedmont in 2011}

Data collected between 2005 and 2009 in Piedmont showed the achievement of a threshold in the number of Internet users, which was difficult to overcome. However the latest PICTO survey, conducted in April 2011, indicates, at last, a growth in the number of Internet users (that has reached the value of $64 \%$ ). Specifically, the next figures (Figure 5 and Figure 6) show the results of the classification analysis conducted in 2011 and the comparison with the results of the previous years.

Looking at the last year tree and comparing it with the previous one (Figure 2) emerges that the group of citizens between 45 and 54 years old can be defined as "new Internet users": this is coherent with the findings of the first part of the paper, where we have shown that non-Internet users younger than 55 years should be the group of citizens more easily and likely included in the Information Society.

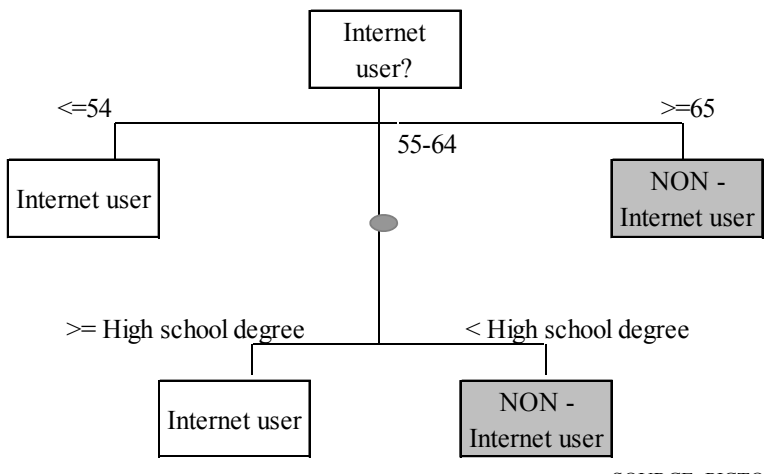

SOURCE: PICTO

Figure 5. Classification tree PICTO data (Internet usage in Piedmont), 2011

\footnotetext{
${ }^{3}$ Eurostat data are available since 2003, otherwise for some countries the value reached in 2003 was bigger than $51 \%$, in the table we put in brackets the value reached in 2003
}

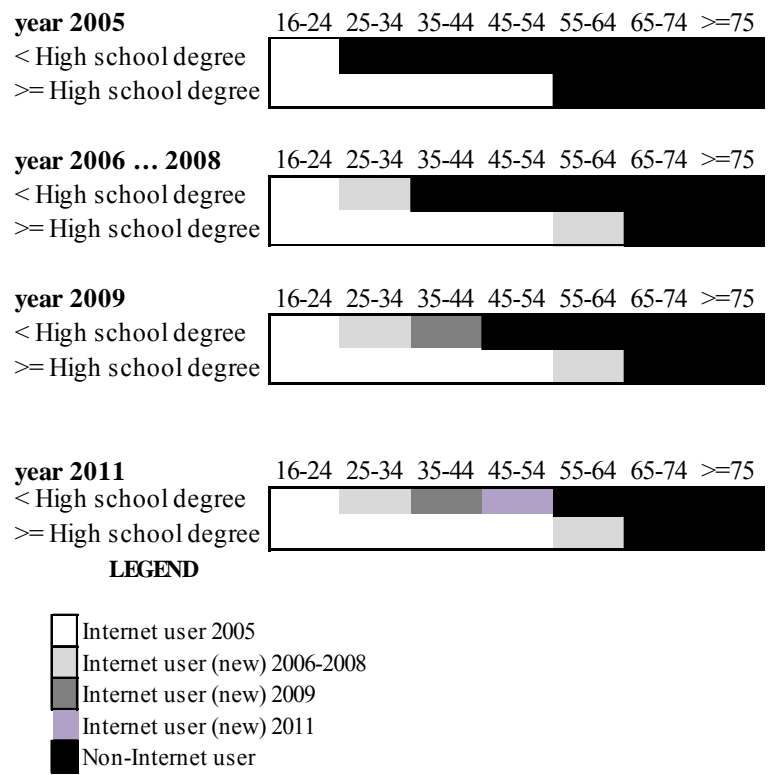

Figure 6. Results of the classification trees (Internet usage in Piedmont), 2005 - 2011

By looking at these considerations, 2 questions emerges: 1) What has happened in Piedmont that justify the enhancement of the number of Internet users?; 2) Which directions should Piedmont policy makers follow for the definition of future e-inclusion policies? In the next chapter a policy analysis will be conducted in order to answer to all those questions.

\section{Policy analysis}

\subsection{Piedmont policies}

In order to explain the increase in the number of Internet users in the last 2 years after a stable period we should identify if and what type of policies have been carried out in Piedmont.

Even if e-inclusion initiatives managed at regional level such as those launched in other European regions (that will be explained in the next paragraph, Table 4) have not been implemented so far in Piedmont, the enhancement of Internet users could be associated to the impact of the WI-PIE program (www.wi-pie.org) started in 2006 and aimed to develop the broadband infrastructure in all the municipalities of the region by 2009 (in 2006 broadband connection was available only in $30 \%$ of the municipalities). The availability of broadband connection has encouraged Public Administrations and enterprises to increase on line services offer and citizens to use the web also for personal purposes. The second stage of the WI-PIE program started in 2009 and will finish in 2013: its main goals are addressed to reinforce on line services offer by Public Administration, to bridge the digital divide in rural areas (using wi-fi solutions) and to strengthen innovation through SMEs. Therefore we 
could imagine that for the next years Internet usage by citizens will increase also in terms of on line activities.

\subsection{European e-inclusion policies}

The second question that, finally, we want to solve regards which directions should be followed by Piedmont policy makers for the definition of future einclusion actions. Even if from the graph in Figure 6 it seems that the gap between Internet and non-Internet users is closing, we believe that the percentage of Internet users should further increase for 2 reasons:

1) for compliance with the regional planning, in fact one of the goals of the second phase of WI-PIE program is to reach $70 \%$ of Internet users in 2013;

2) as an alignment to the European trends. Table 5 shows the percentage of Piedmont Internet users in 2011 and compare this value with the one reached by some of the countries to which the Italian region has been benchmarked in the previous part of the article: in almost all of the cases the value already exceeds the $75 \%$.

Table 5. Percentage of Internet users in Piedmont and in other comparable European countries in 2011

\begin{tabular}{|c|c|c|}
\hline & Country & \% Internet users (2011) \\
\hline & Piedmont & $64 \%$ \\
\hline \multirow{6}{*}{ 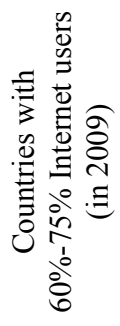 } & Ireland & $73 \%$ \\
\hline & Latvia & $71 \%$ \\
\hline & Slovakia & $83 \%$ \\
\hline & Estonia & $78 \%$ \\
\hline & Austria & $77 \%$ \\
\hline & Belgium & $82 \%$ \\
\hline \multirow{5}{*}{ 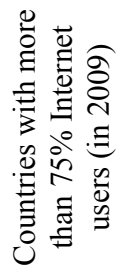 } & Finland & $89 \%$ \\
\hline & Denmark & $91 \%$ \\
\hline & Netherlands & $92 \%$ \\
\hline & Sweden & $93 \%$ \\
\hline & Norway & $95 \%$ \\
\hline
\end{tabular}

Considering the high Internet usage levels already reached by these countries, an analysis of European einclusion policies could be useful to understand towards which direction future policies could be addressed in Piedmont.

The European action plan i2010 has set some goals in order to obtain a better development of Information Society in all countries. The plan indicates 13 guidelines [20] regarding different issues such as services offer, infrastructure, enterprises development, support to the innovation and social inclusion, indeed. The eighth guideline 'Further development of
eAccessibility and a comprehensive eInclusion strategy', is strictly related to e-inclusion matters.

Furthermore the analysis of digital literacy initiatives [19] underlines that the phenomenon of digital divide is composed by 3 stages concerning at first access problems, then skills problems and finally difficulties in a mature Internet usage. This is coherent to the model proposed by Van Dijk [3]. Specifically, the digital literacy initiatives can be classified in four groups: 1) Motivation: This kind of initiatives are aimed at boosting motivation and raising awareness on ICT, in this way the most frequently cited reason for not having the Internet at home - no perceived need or lack of interest in using it - could be overcome. It is important to suggest to the potential new Internet user all benefits of using the Internet such as time / money saving, easier communication, usage of services suitable for everyday life. In these initiatives "intermediaries" have an important role to approach people with the ICT. 2) Affordability and sustainability: in this case are collected all initiatives aimed at assuring availability of PC and Internet (at lower prices) in all families and public offices. 3) Content and delivery mode: some actions are addressed to web content and services offer. Content should fit personal interests of people not using the Internet yet: these citizens should understand its utility and ride out their fears, for example through intermediaries or informal learning. 4) Accessibility and usability: at least some initiatives that promote accessible services for every user are promoted. They use adequate interfaces and support an easy learning.

In Table 4, as example, some European initiatives are listed. In the first column of the table there is a short description of each initiative, while in the second column the main points that will be useful for the definition of future policies are summarized. The table shows a delay in the implementation of e-inclusion policies between Piedmont and other comparable European regions: almost all the initiatives considered started already in 2000 and are aimed to cope with the problems that have been identified in the previous part of the paper.

\subsection{Policy remarks}

Considering both the characteristics of the population and the quality of e-inclusion policies implemented in the European regions, this research leads to the definition of some suggestions that could be addressed to policy makers that want to plan future policies of e-inclusion in a region where, even though the contextual background is quite good (looking at economic indicators - income, GDP - it is similar to the richest regions of Europe), the percentage of Internet users is still too small. 
Table 4. Examples of e-inclusion initiatives in Europe

\begin{tabular}{|c|c|}
\hline INITIATIVE & FOCUS \\
\hline $\begin{array}{l}\text { Mukanetti (Finland) (since 2000) } \\
\text { OBJECTIVE: promote equality inter } \\
\text { generations }\end{array}$ & $\begin{array}{l}\text { Training of older } \\
\text { people } \\
\text { Remove fear towards } \\
\text { ICT }\end{array}$ \\
\hline $\begin{array}{l}\text { IT for the terrified (UK) (since1999) } \\
\text { OBJECTIVE: informal training } \\
\rightarrow \text { training section in familiar and } \\
\text { friendly athmosphere managed by } \\
\text { volunteers } \\
\text { Attention to everybody needs }\end{array}$ & Informal training \\
\hline $\begin{array}{l}\text { Grandparents \& Grandchildren (EU, } \\
\text { since 2007) } \\
\text { OBJECTIVE: tackle digital divide and } \\
\text { develop inter generational dialogue } \\
\rightarrow \text { ICT training in a easy and familiar } \\
\text { way }\end{array}$ & $\begin{array}{l}\text { Importance of } \\
\text { intermediaries in the } \\
\text { approach to the ICT } \\
\text { of older people }\end{array}$ \\
\hline $\begin{array}{l}\text { UK Online centres (UK) (since 2000) } \\
\text { OBJECTIVES: } \\
\text { - promote public Internet / PC access } \\
\text { - improve quality of life } \\
\text { - reinforce sense of community } \\
\text { - social inclusion }\end{array}$ & $\begin{array}{l}\text { Promote Internet } \\
\text { access from who has } \\
\text { not Internet at home } \\
\text { Reinforce sense of } \\
\text { community }\end{array}$ \\
\hline $\begin{array}{l}\text { Digital Communities (Ireland) (since } \\
\text { 2003) } \\
\text { OBJECTIVE: action for places in } \\
\text { qhich there i san high unemployment } \\
\text { rate and lower education level } \\
\text { Training and creation of community } \\
\text { ICT centres }\end{array}$ & $\begin{array}{l}\text { Support to } \\
\text { unemployed and } \\
\text { citizen with lower } \\
\text { education level }\end{array}$ \\
\hline
\end{tabular}

The first issue has to do with the purpose of using the Internet. Citizens that are out of the Information Society will approach ICTs when they will perceive its utility for their everyday life. This is the reason why, the promotion of Internet usage for personal purposes and not only for professional aims, should be encouraged. For example, younger non-Internet users, that are almost all workers, say that they do not use the Internet because they do not have time. In this case policy makers should think about how Internet usage would help this group of people providing useful and easy services. Moreover, the awareness on the benefits that Internet could provide to people, in particular for the group of non-Internet users more approachable (under 55 years old), should be increased by: 1) using more familiar technologies (eg. mobile phone, television) to which also non-Internet users are accustomed to; 2) promoting Internet access in public places where citizens that now are excluded from the Information Society are used to meet: in this way they would begin to know the potentialities of Internet and they would try to use it with the help of familiar people; 3) encouraging informal training, also through the role of friends and relatives that will help them in the use of the Internet (intermediaries); 4) advertising on Internet use through traditional channels (radio, TV), in order to increase the awareness about services offered and all benefits that Internet could bring in everyday life. At least it should be important to pay attention to services offered on line: not always they are easy to use and sometimes citizens are not aware of their existence.

\section{Conclusions}

This paper has investigated digital divide, considered as differences between Internet users and non-users, in a European region. Even though research on this topic has been carried out in the past, we propose a framework that, thanks to the analysis of factors and motivations that block citizens in using the Internet and through a benchmarking between comparable European regions, leads to the identification of adequate policies that could be implemented in a region that has to cope with problems related to the inclusion of citizens in the Information Society. The main findings of the research can be summarized in the following points.

1) Age and education are the main variables that determine Internet usage.

Focusing on data collected in Piedmont, through multivariate data analysis the variables that determine Internet usage have been discovered and then they have been taken into account when analysing motivations for not using the Internet. In the case of Piedmont region this kind of analysis showed that Internet usage is mainly influenced by age and education and that, focusing on non-Internet users, the motivation for not using the Internet varies from time and access problems to a lack of interest as the age of the respondent increases. Furthermore non-Internet users have also a lower education level than Internet users.

2) For similar European regions differences in the characteristics of the population influence the Internet usage rate reached.

In a second phase of the study the region has been analyzed in the European context. Specifically, Piedmont has been benchmarked with other regions, considering both socio - economic features both Internet usage rates. This comparison showed that, even if Piedmont is similar to the richest and most developed European regions, the Internet usage rate is still low. Instead, the main differences are related to the education level, to the ageing of the population and to the industrial structure of the region.

3) The definition of new e-inclusion policies should meet non-users needs and features.

Lastly, through the benchmark analysis conducted the lag between Piedmont and the regions in which the Internet usage rate is higher has been measured. In order to help Piedmont region to understand how to make up for the delay a policy analysis has been carried out. Even if we have observed that Piedmont region, after some years of stagnation, in 2011 has been able to bridge digital divide in terms of "motivational access" thanks to WI-PIE program, we believe that in the next years the number of Internet users in the region should further increase for 
compliance with the regional planning but also as an alignment with the European trends. In particular the policy suggestions that this article provides consider the characteristics of the population and the e-inclusion policies launched in other European regions. In the case of Piedmont region the group of individuals that more easily could be integrated in the Information Society has been identified in younger non-Internet users: older non Internet users are, in general, simply not interested in the technologies, while younger citizens complain the lack of time and access difficulties. These last problems are more tangible than "not interest" and give more precise indication about non users needs to policy maker that have to plan new policy actions. Moreover the study highlights that the number of Internet users will increase if citizens perceive ICT utility for their everyday life and not only for school or work purposes. In addition, policy makers should be aware of the difficulties in using ICT argued by non-users and define new policies that meet non-users needs. For this purpose they could consider the provision of on line services through technologies to which all citizens are accustomed (mobile phone, television) and promote Internet access in public places. Furthermore non Internet users should increase their consciousness of the benefits of Internet in their life. To this aim the role of the social network is fundamental: friends and relatives should help nonInternet users in adopting the new technologies, but also information provided through traditional channels (radio and TV) will play a key role.

A potential limitation of this research is given by data constraints in the comparison between Piedmont and European regions, in fact we have considered 2 different data source: PICTO (for Piedmont) and Eurostat (for European regions). Even if these 2 data sources do not offer information with the same detail, we have been able to exploit a regional problem (using PICTO disaggregated data) to the European context (using Eurostat aggregate data that confirmed our previous findings). Future research could integrate the analysis on the differences between Internet users and non users with a study on the behavior of citizens over the Internet.

\section{References}

[1] European Commission, "Study on the Social Impact of ICT", 2010.

[2] OECD, "Glossary of statistical terms", http://stats.oecd.org/glossary/detail.asp?ID=4719, 2001.

[3] J. Van Dijk, "Digital divide research, achievements and shortcomings", Poetics, 34(4-5): p. 221-235, 2006.

[4] R.E. Rice, J.E. Katz, "Comparing Internet and mobile phone usage: digital divides of usage, adoption, and dropouts", Telecommunications Policy, 27(8-9): pp. 597-623, 2003.

[5] N. Selwyn, "Digital division or digital decision? A study of non-users and low-users of computers", Poetics, 34(4-5): pp. 273-292, 2006.

[6] H. Di Maggio, E. Hargittai, C. Celeste, S. Shafer "Digital inequality: from unequal access to differential use", The inequality reader, 2007.

[7] K. Roe, A. Broos., "Marginality in the Information Age: The Socio-Demographics of Computer Disquietude", Communications: The European Journal of Communication, 30 (1):pp. 91-96, 2005.

[8] Z. Kovacic, D. Vukmirović, "ICT Adoption and the Digital Divide in Serbia: Factors and Policy Implications". Proceedings of the Informing Science \& IT Education Conference, 2008.

[9] M.R. Vicente, A.J. López, "Assessing the regional digital divide across the European Union-27", Telecommunications Policy, 35 (3), pp. 220-237, 2011

[10] R. Agarwal, A. Animesh, K. Prasad, "Social interactions and the "previous termdigital dividenext term': Explaining regional variations in Internet use", Information Systems Research , 20 (2): pp. 277-294, 2009.

[11] L. Andrés, D. Cuberes, D. Mame, T. Serebrisky, "The diffusion of the Internet: A cross-country analysis", Telecommunications Policy, 34 (5-6): pp. 323-340, 2010.

[12] M. Billón, R. Ezcurra, F. Lera-López, "The spatial distribution of the Internet in the European Union. Does geographical proximity matter?", European Planning Studies, 35 (3):pp. 119-142, 2008.

[13] BISER ,"BISER eEurope Region. Benchmarking Report", 2004.

[14] M.D. Chinn and R.W. Fairlie, "The determinants of the global previous termdivide: cross-country analysis of computer and Internet penetration", Oxford Economic Papers, 2007.

[15] P. Verdegem, P. Verhoest, "Profiling the non-user: Rethinking policy initiatives stimulating ICT acceptance". Telecommunications Policy, 33: pp. 642652, 2009.

[16] E. Ferro, N.C. Helbig, J.R. Gil-Garcia, "The role of IT literacy in defining digital divide policy needs", Government Information Quarterly, 28(1): pp. 3-10, 2011.

[17] M. G. Quibria, S.N. Ahmed, T. Tschang, M. ReyesMacasaquit "Digital divide: determinants and policies with special reference to Asia" Journal of Asian Economics, 13(6): p. 811-825, 2003. 
[18] R.M. O'Brien, “A Caution Regarding Rules of Thumb for Variance Inflation Factors", Quality \& Quantity, 2: pp. 673-690, 2007.

[19] European Commission, "Digital Literacy European Commission Working Paper and Recommendations from Digital Literacy High-Level Expert Group", 2008.

[20] European Commission, "Europe's Digital Competitiveness Report, Main achievements of the i2010 strategy 2005-2009, i2010 - List of actions" 2009. 